\title{
Pyramidal structure, firm capital structure exploitation and ultimate owners' dominance.
}

\begin{abstract}
In this paper we investigate how pyramid structure, separating cash flow rights and control rights, allows ultimate owners to control the company's resources for the creation of private benefits and to avoid punishment for such conduct. Empirical tests are conducted using threestage least squares regression. The estimated results provide support for the hypotheses proposed that the separation of cash flow rights and control rights have led to the use of excess leverage among pyramidal companies to preserve ultimate owners' control. High levels of leverage, affect the firm's valuation negatively because of the potential for financial distress. Thus, our findings may provide one additional explanation for the severity of the decrease in corporate value among the pyramidal companies in Malaysia as pointed out in the studies of Claessens et al. (2002), Lins (2003), and Lemmon and Lins (2003). Secondly, the empirical evidence from this study provides insight into the forces that influence corporate valuation of firms in developed countries particularly those that have pyramidal structure.
\end{abstract}

Keyword: Pyramidal structure; Ultimate owners; Capital structure; Financial distress; Firm value. 